\title{
Arbor
}

\section{Funciones y problemas de los correos que acompañan a las Obras de Arte en su itinerancia}

\section{Antonio Rocha Nicolás}

Arbor CLXIV, 645 (Septiembre 1999), 109-118 pp.

La preocupación y el cuidado en el embalaje y la manipulación de obras de arte durante los traslados entre diversos países, no es algo que haya surgido recientemente, sino que se remonta a varios siglos atrás.

Tenemos constancia de que ya en el siglo XVI, Felipe II, rey de España, mantuvo una abundante correspondencia con distintos personajes para asegurarse de que las obras de Tiziano que tenían que serle enviadas gozaran de las mayores garantías, aunque no siempre lo conseguiría. Así, escribió al recibir una versión de la fábula mitológica de Venus y Adonis, en 1554: "El quadro de Adonis que acabó Tiziano ha llegado aqui, y me paresce de la perfección que dezis, aunque vino maltratado de un doblez que traía al través por medio dél, el qual se devió hazer al cogelle, verse ha el remedio que tiene".

En esa misma época le fue enviado un "Santo entierro", que se perdió durante el viaje y jamás se volvió a saber de él. A raíz de este incidente el rey dió ordenes para tener más cuidado en sucesivas expediciones. Dispuso un sistema para seguir paso a paso el traslado de las obras, haciendo responsable de cada etapa a los representantes del reino de España en Italia: en Génova el embajador Juan de Figueroa, en Venecia el secretario de la Embajada Española, García Hernández, en Milán, el gobernador Marqués de Pescara. Para evitar este tipo de problemas, el rey mandó una carta dando instrucciones concretas: "... porque no suceda el inconveniente que sucedió a la 


\section{Antonio Rocha Nicolás}

pintura del Cristo, he acordado que se embie a Génova para que de allí se me encamine a España, y scrivo a García Hernández sobrello. Vos se las entregareis a él y procurareis que vaian muy bien puestas en su caxas y enpacadas de manera que no se gasten en el camino y para esto sera bien que vos que lo entendeis las pongais de vuestra mano porque sería gran pérdida que llegassen dañadas». En 1561, el rey mandó hasta cuatro cartas interesándose por el transporte de varios cuadros y recomendando los criterios fundamentales del envío: rapidez y seguridad. Para ello, se decidió hacer el viaje separando los cuadros: unos irían por Milán y los otros por Génova. El interés del monarca por las obras de Tiziano queda reflejado en una anotación de su puño y letra al recibir el cuadro de la Última Cena: "Hoy ha traído aquí un criado de D. Álvaro de Bazán dos caxas, la una, la roja en que ha venuta la cena, bien tratada en dos pieces, y no hay más pinturas..." lo que constituye un primitivo y esquemático informe del estado de conservación del cuadro.

Actualmente, y debido al auge que ha experimentado el préstamo de obras de arte entre museos e instituciones de todo el mundo, se han de extremar las precauciones durante los traslados y mientras dure la exposición. Buena parte de estas responsabilidades recaen en los restauradores encargados de supervisar las exposiciones itinerantes.

Vamos a diferenciar los distintos cometidos en función de que la muestra sea en el propio Museo, con obras ajenas o propias, que vengan acompañadas de correos, etc.

La exposición en el propio Museo con obras ajenas al mismo:

Si las obras vienen acompañadas de correo, estaremos con él en cada una de las fases del proceso.

En el desembalaje tomaremos nota detallada de las características del mismo; si la caja es de madera, metálica, o de otro tipo, y el estado en que ha llegado.

La envoltura también cumple un papel importante, anotaremos si es glassine, tisú, plástico, etc.

En las cajas múltiples, con varias obras, hay que tener en cuenta el orden de colocación de las mismas, si es necesario, hacer un croquis, o mejor aún fotografiar cada piso o plano de la caja.

También es necesario fijarse si la capa pictórica está hacia arriba o hacia abajo.

Comprobar que la numeración de la caja y de las obras que contiene, coinciden con la lista que estamos manejando. Si no vienen numeradas, conviene que lo hagamos nosotros. 
Todas estas anotaciones son muy útiles porque hay que prever la posibilidad de que a la recogida de las obras no venga el mismo correo y hay que devolverlas en las mismas condiciones en que llegaron.

Una vez hayamos desembalado, comprobaremos con el correo los informes que traiga, reflejando en los mismos cualquier incidencia que haya ocurrido. Es conveniente que se haga una fotocopia de éstos, para hacer anotaciones durante el tiempo que dure la exposición, como mediciones periódicas de temperatura y humedad relativa, daños que puedan sufrir, alteraciones, etc.

Hay unas normas básicas que se deben exigir al equipo de montaje, como son: puestas.

- No fumar mientras se manipulan las obras, ni donde van a ser ex-

- Usar guantes de algodón, excepto cuando el objeto sea resbaladizo o que por su forma exista el riesgo de que la tela de los guantes se enganche en la obra.

- Antes de mover la obra, saber exactamente lo que se va hacer con ella y donde va a colocarse. una.

- Por pequeñas que sean las obras, se deben manipular de una en

- Cuando pueda existir peligro de caída, hay que manejar la obra entre dos personas.

- Moverse con cuidado y lentamente cuando se traslada el objeto.

- No transportar en el mismo vehículo o carro objetos de tamaños y formas diferentes.

-Manipular las obras lo menos posible.

\section{Obras enmarcadas:}

- En el caso de obras pictóricas, no tocar la parte frontal ni el reverso y no permitir que nada apoye, ni siquiera ligeramente, sobre ninguna de las superficies.

- Antes de mover la pintura, asegurarse de que está firmemente enmarcada.

- Comprobar que el sistema para colgar la obra es lo suficientemente seguro.

- Transportar las pinturas sujetándolas con una mano por debajo del marco y la otra por un lateral del mismo (si son dos personas), o con ambas manos en los costados si es una obra pequeña y la mueve una sola persona.

- No apoyar nunca un cuadro en el suelo por una de las esquinas. 
- No introducir los dedos entre el bastidor y la parte posterior de la tela.

- No utilizar cinta adhesiva en el anverso, ni en el reverso de la pintura, tampoco en las partes visibles del marco.

- No apilar cuadros cuyos marcos sobresalgan, sino que estén en el mismo plano de la tela.

- No hacer pilas de cuadros muy grandes, ya que el peso puede dañar los marcos.

- Entre cuadros con marcos delicados y ornamentales poner algún tipo de protección.

- $\mathrm{Al}$ apilar varios cuadros, apoyar el primero lo más vertical posible y que sean de tamaños similares, los más grandes al fondo y los más pequeños al frente. El cuadro siguiente debe cruzar completamente al otro. Entrecruzar los cuadros frente con frente y reverso con reverso.

- Apoyar en una superficie o suelo no resbaladizo (goma o tela).

- Los cuadros deben mantener la posición vertical mientras estén en movimiento, excepto en casos en que su estado de conservación aconseje lo contrario.

\section{Obras sin marco:}

- Se debe levantar la hoja de papel, sujetándola por las esquinas superiores, de manera que cuelgue libremente y no se produzcan ondulaciones.

- Mantener las obras planas y cara arriba.

- Depositar las obras sobre cartones neutros y limpios para su traslado.

- Las obras sobre papel delgado deben ser transportadas en un portafolio o caja especial de cartón neutro.

- Las obras a carboncillo, lápiz, pastel, etc., deben ir en un estuche especial en forma de libro, de cartón neutro, con ventana o separación para evitar roces al cerrarlo.

- Las obras montadas en soportes neutros se pueden apilar poniendo una hoja de separación de papel $\mathrm{pH}$ neutro.

- Se deben apilar pocas obras y de tamaño similar, teniendo la precaución de colocar las más grandes abajo.

\section{Esculturas:}

- Nunca se debe manejar una escultura por las partes sobresalientes. 


\section{Funciones y problemas de los correos...}

- Proteger las esculturas en tránsito con mantas, paños acolchados, etc. y que las partes sobresalientes no descansen en la base del vehículo. El peso debe repartirse equitativamente.

- Si es posible, se deben almacenar las esculturas y transportarlas en la misma posición en que se exponen.

- Las esculturas de metal no se deben tocar nunca sin guantes porque las huellas pueden dañarlo.

- Las esculturas de mármol o piedra, al ser más porosas absorben la suciedad y la grasa con facilidad, por eso no deben tocarse sin guantes.

- Para manipular esculturas pequeñas debe sostenerse la obra con una mano por la base y afirmar el cuerpo de la obra con la otra.

- Para manejar esculturas de gran tamaño o muy pesadas debe utilizarse una carretilla o carro apropiado, con amortiguación especial, levantándola con grúas hidráulicas para colocarlas en el carro, nunca arrastrar las esculturas.

Una vez revisadas todas las obras y de conformidad con el correo, se firmarán los informes.

Concluída la exposición se volverán a revisar las obras con el correo que venga y se procederá a su embalaje siguiendo las anotaciones que se hicieron, de forma que no haya diferencias entre la llegada y la salida.

En el caso de que las obras vengan sin correo, deberemos seguir los mismos pasos respecto al embalaje, anotando cuidadosamente todas las características, haciendo constar además en nuestro informe quien es el propietario de cada obra, o el museo, galería, institución, etc. de que proceden. Esto es importante, ya que en exposiciones antológicas, de un solo autor, se suele dar el caso de que haya varias obras del mismo formato y medidas, hechas en el mismo año y con idéntico título, por lo que necesitamos identificarlas mediante la numeración y la constancia del prestador de cada una de ellas. Cuantos más datos tengamos, más nos facilitará el trabajo: título, autor, medidas, datación, técnica, propietario, . prestador, etc.

Dado que no hay acompañante y por tanto carece de informe, deberemos hacer uno muy detallado del estado de la obra a su llegada, haciendo hincapié en aquellos aspectos susceptibles de variación, debido a las condiciones climáticas y ambientales: si son obras sobre lienzo, observar el posible alabeo del bastidor, el tensado de la tela, presencia de xilófagos y hongos, etc. En obras sobre papel, comprobar si hay deformaciones del mismo, foxing, falta de adhesividad en los elementos pegados de los collages, oxidaciones... En piezas de madera, vigilar si hay curvaturas en los paneles, astillamientos, piezas desencoladas, etc. En todas las obras enmarcadas, prestar atención a las condensaciones en el interior de los 


\section{Antonio Rocha Nicolás}

cristales o metacrilatos que pueden provocar manchas de humedad y favorecer la aparición de microorganismos.

Estas observaciones no sólo son válidas en el momento de la recepción de las obras, sino que exigen un seguimiento continuo, haciendo revisiones periódicas que incluyan mediciones de temperatura, humedad relativa, iluminación, etc. con gráficos de termohigrógrafo, que se adjuntarán a los informes, así como cualquier incidencia que ocurra durante la muestra, como accidentes, caída de la obra, vandalismo, etc.

En cualquiera de estos supuestos, hay que dar cuenta inmediatamente al propietario o prestador y a la compañía aseguradora, absteniéndonos de efectuar cualquier intervención o restauración sin contar con el permiso y autorización expresa de los mismos. Se les remitirá una copia del informe de llegada, con las sucesivas mediciones efectuadas (al menos una por semana) y una explicación detallada del incidente acaecido, con gráficos y fotografías. Asimismo, conviene tener prevista una propuesta de tratamiento y estimación de su duración por si nos lo solicitan.

A continuación vamos a tratar otro caso similar pero con aspectos propios que debemos considerar:

La exposición la organiza nuestro Centro, con obras propias y ajenas, que va a viajar posteriormente, siendo responsable de la itinerancia el mismo Centro.

Durante la exposición lo tenemos más fácil, puesto que se supone que disponemos de informes completos de nuestras obras. De las que nos lleguen como en el caso anterior, haremos informes con croquis, fotografías, mapas de desperfectos, etc.

Hay que ponerse en contacto con la empresa que se va a encargar del transporte en los sucesivos viajes, por varias razones. En primer lugar, elaborar una lista, que internacionalmente se denomina packing list en

- la que figuran todas las obras de la exposición, con su título, autor, medidas (con y sin marco), técnica, fecha de ejecución, propietario o prestador a quien hay que devolverla, y sobre todo numeración de la obra y referencia de la caja en la que va a ser embalada. Esto es importante y debe ser mantenido a lo largo de toda la itinerancia. Esta relación nos va a servir también para clasificar los informes y poder archivarlos correlativamente.

En segundo lugar y puesto que las obras van a viajar, hay que medir lo más exactamente posible cada una de ellas con su marco para que la empresa encargada del transporte fabrique las cajas adecuadas. Una vez hechas éstas, comprobar que las obras encajan perfectamente, sin holguras, que tienen el aislante necesario y disponen de asas, agarraderas $u$ 
Funciones y problemas de los correos...

otros elementos para poder manejarlas cómodamente, que no sobresalen clavos o tornillos, etc. y que muestren en su exterior la rotulación adecuada, con su número de embalaje, los números de las obras que contienen y las flechas indicadoras de su posición correcta. Ésta rotulación debe ser visible en cualquier posición y desde cualquier ángulo, por lo cual tiene que ir tanto en la tapa y en la trasera como en los laterales.

Las cajas deben ser de madera sólida, aislantes, impermeables, acolchadas con materiales flexibles para evitar golpes y vibraciones, revestidas de algún material ignífugo. Las esquinas deben ir reforzadas. Todas las cajas llevarán listones a lo largo de las mismas y asas para su manejo, irán cerradas con tornillos, nunca con clavos. Para objetos sumamente frágiles se usarán dobles cajas.

Las obras dentro de la caja irán envueltas en materiales porosos (papel), nunca con plástico, para evitar condensaciones de humedad.

Las obras con vidrio llevarán cubierto éste con tiras de cinta adhesiva, para que en caso de rotura no dañen a la obra, aunque sería más aconsejable sustituir el vidrio por metacrilato. En este caso no se pondrá la cinta adhesiva sobre el metacrilato ni tampoco sobre el marco.

En casos de pequeñas obras enmarcadas, como dibujos de poco peso, las cajas pueden ser múltiples o acanaladas, con raíles o correderas.

Para objetos tridimensionales, las cajas de madera en su interior pueden llevar dos sistemas: 1) el objeto se acomoda a una cavidad adaptada a su contorno, realizada con espuma de polietileno y forrada con un material suave, que también debe cubrir la parte superior. 2) caja con soportes internos que se deslizan por correderas, asegurando la obra dentro de la caja (guillotina). La parte del soporte que está en contacto con la escultura, debe estar acolchada con esponja de goma y felpa, así como el piso inferior, que estará forrado con el mismo material.

En el interior de las cajas pueden instalarse medidores de golpes (pequeñas etiquetas transparentes con un líquido rojo que mida la intensidad de las vibraciones), de humedad, temperatura, etc.

Actualmente se están fabricando cajas en aluminio, igualmente aisladas y acondicionadas, con un bastidor interior flotante, que se adapta a diferentes medidas.

Los traslados de las obras se realizan por carretera, tren, avión o barco, dependiendo de su volumen y peso.

El transporte por carretera debe ser en camiones acondicionados y blindados. En su interior se tiene que mantener una temperatura y humedad constantes, han de llevar una amortiguación especial para minimizar las vibraciones o golpes y deben estar provistos de una plataforma elevadora que permita subir y bajar las cajas con facilidad. Éstas irán sujetas en el interior del camión mediante un sistema de correas que las 


\section{Antonio Rocha Nicolás}

mantenga fijas. Una vez colocadas, se sella la cerradura, con un número que llevará la persona que acompaña a las obras. El camión no se volverá a abrir hasta que llegue a su destino y siempre en presencia del correo, se comprobará el número lacrado.

El medio de transporte más utilizado para viajes intercontinentales es el avión y es importante elegir vuelos, a ser posible, sin escalas.

El traslado en barco es el menos utilizado, y sólo es aconsejable en caso de que el tamaño o el peso de las obras no permita ninguno de los descritos anteriormente, como por ejemplo cuando se trata de esculturas monumentales.

En este medio de transporte, las cajas utilizadas deben ser dobles, ir fuertemente atadas e impermeabilizadas.

Una vez en su destino se abrirán en presencia del correo. Si éste no ha acompañado a las obras, los informes irán dentro de cada caja para que quede constancia de cualquier alteración sufrida durante el viaje.

Por último, conseguir que la empresa de transportes designe un interlocutor único con el que poder dialogar y que nos mantenga informados de todas las circunstancias, como empresas corresponsales en los lugares o países destinatarios, trámites aduaneros, escolta policial si es necesaria, seguros, permisos de importación-exportación, fletes aéreos, transportes por carretera, alojamiento, pasajes, comunicaciones con embajadas o delegaciones consulares, teléfonos de contacto tanto en el país de origen como en el de destino, por si hay alguna emergencia, etc.

Muchas de estas funciones se gestionan también desde el museo, por lo que es necesario estar en permanente comunicación con el departamento responsable de las mismas.

Al terminar la exposición y durante el embalaje, deberá estar presente la persona que acompañará a las obras en el viaje, comprobando que los informes previos se corresponden con el estado actual de las obras, y en caso de que haya alguna alteración se reflejará en los mismos.

Como ya he comentado, hay que prestar especial atención a la numeración de las obras. A medida que se van embalando, se hará una señal en el packing list para asegurarnos de que todas las obras están en sus cajas y que éstas tienen la identificación correspondiente.

Cuando manejamos una exposición con muchas cajas nos puede ser muy útil señalar las que ya están llenas, por ejemplo con una simple cinta plástica, y colocarlas juntas y en sitio diferente a las vacías para evitar equivocaciones.

Antes de iniciar el viaje, deberemos aclarar qué organismo o institución se hará cargo de las gestiones y los gastos: seguros, transportes, trámites aduaneros, dietas (perdiem o viático), hay que confirmar con el mismo su cuantía y que nos comuniquen cuándo y dónde se hará efectiva. 


\section{Funciones y problemas de los correos...}

Hay que exigir un plan pormenorizado del viaje, con los horarios de los vuelos, llegada al centro de exposición, hora y día del desembalaje. En el caso de que viajen por vía aérea, conviene que las cajas permanezcan por lo menos 24 horas en el lugar de exposición antes de abrirlas, para que las obras se vayan aclimatando paulatinamente a las nuevas condiciones ambientales.

Igualmente, hay que confirmar la reserva del pasaje de vuelta y el alojamiento en el hotel.

En los viajes al extranjero, deberemos contactar con las embajadas o delegaciones consulares correspondientes para saber qué condiciones se exigen para entrar en cada país, como visados, algún tipo de vacunación o cualquier otro requisito y enterarnos del clima local por si hay que tomar alguna precaución respecto a la carga, y también para saber qué indumentaria tenemos que llevar.

Es conveniente que nos hagamos un listado con los teléfonos más importantes, como es la empresa encargada de los transportes y gestiones en el país de destino, así como la embajada o consulado, el centro de exposición, la dirección del hotel, etc. Estipular que nos estén esperando en el aeropuerto con un vehículo apropiado para el traslado de las cajas hasta su lugar de exposición.

Una vez todo en regla nos disponemos a emprender el viaje. Si es en avión, lo primero que hay que hacer es armarse de paciencia, ya que tenemos por delante horas de espera en aeropuertos, aduanas, etc.

Acompañaremos las cajas hasta la terminal de carga procurando estar lo más cerca posible de ellas o al menos no perderlas de vista, hasta que estén paletizadas. En ese momento, tomaremos nota de los números de los paléts. Antes de subir al avión, en la misma puerta de embarque pediremos al jefe de escala o algún otro responsable de la compañía aérea que comprueben si los paléts cuyos números apuntamos han embarcado. $\mathrm{Si}$ es así, tendremos unas horas de descanso durante el vuelo. Al llegar al destino, nos estarán esperando para ir a la terminal de carga y recoger las cajas después de cumplimentar todos los trámites aduaneros, lo que se puede alargar varias horas, dependiendo de la burocracia de cada país.

Cuando lleguemos al lugar de la exposición dejaremos las cajas sin abrir al menos durante 24 horas. Al día siguiente se procederá al desembalaje con un equipo de profesionales con experiencia. Como esto no siempre es posible, vigilaremos atentamente la manipulación de las obras.

Deberemos insistir, en que por mucha urgencia que haya, las cajas deben abrirse de una en una bajo nuestra constante supervisión, manejando las obras con guantes y dando tiempo a examinar cada una de ellas. Procuraremos no dañar demasiado las envolturas de glassine, 


\section{Antonio Rocha Nicolás}

118

tissú, etc. y las guardaremos en la misma caja, así como tornillos y elementos de sujeción.

Trabajaremos en estrecho contacto con el restaurador del centro responsable de la exposición y con él, comprobaremos los informes del estado de conservación y mediremos las condiciones ambientales: temperatu$\mathrm{ra}$, humedad relativa, intensidad lumínica y le pediremos que mientras dure la muestra realice mediciones semanales de dichos factores, tal como hacemos nosotros en nuestro Museo.

Es conveniente dejarle también los informes y packing list con todas las anotaciones que hemos ido haciendo y las características del embalaje, ya que a veces no es posible que la recogida de la exposición la haga el mismo correo que la ha llevado y es importante que disponga de la mayor información posible para facilitarle su tarea.

El proceso de devolución de las obras es básicamente el mismo que el de la llegada, pero hay un aspecto en el que debemos mostrarnos especialmente insistentes: los trámites aduaneros. Tenemos que conseguir que algún organismo competente, como puede ser el centro donde se exhibe la muestra, la embajada, el Ministerio de Asuntos Exteriores, o cualquier otro, contacte con las autoridades aduaneras para que la inspección correspondiente se realice en el momento de embalar las obras, y en el mismo centro donde se han expuesto, evitando, así, el tener que abrir las cajas en la terminal de carga, con el consiguiente riesgo para las obras, dado que generalmente están en lugares donde abunda el polvo y la suciedad y donde las condiciones ambientales no son las adecuadas. Estas gestiones requieren su tiempo, por lo que deberemos advertirlo al comienzo de la exposición para que no haya problemas de última hora. 